Fin

JURNALU (a)

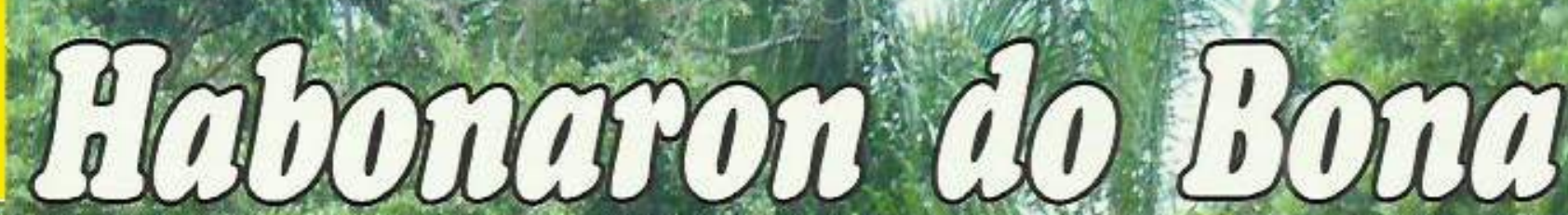

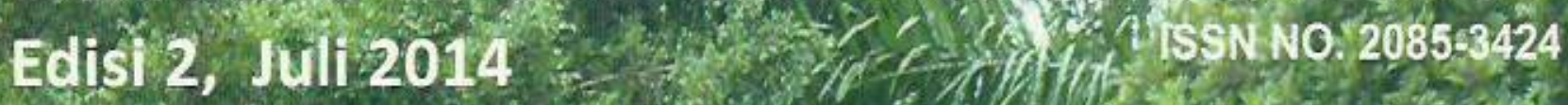
LPPM - UnVersitas simalungun

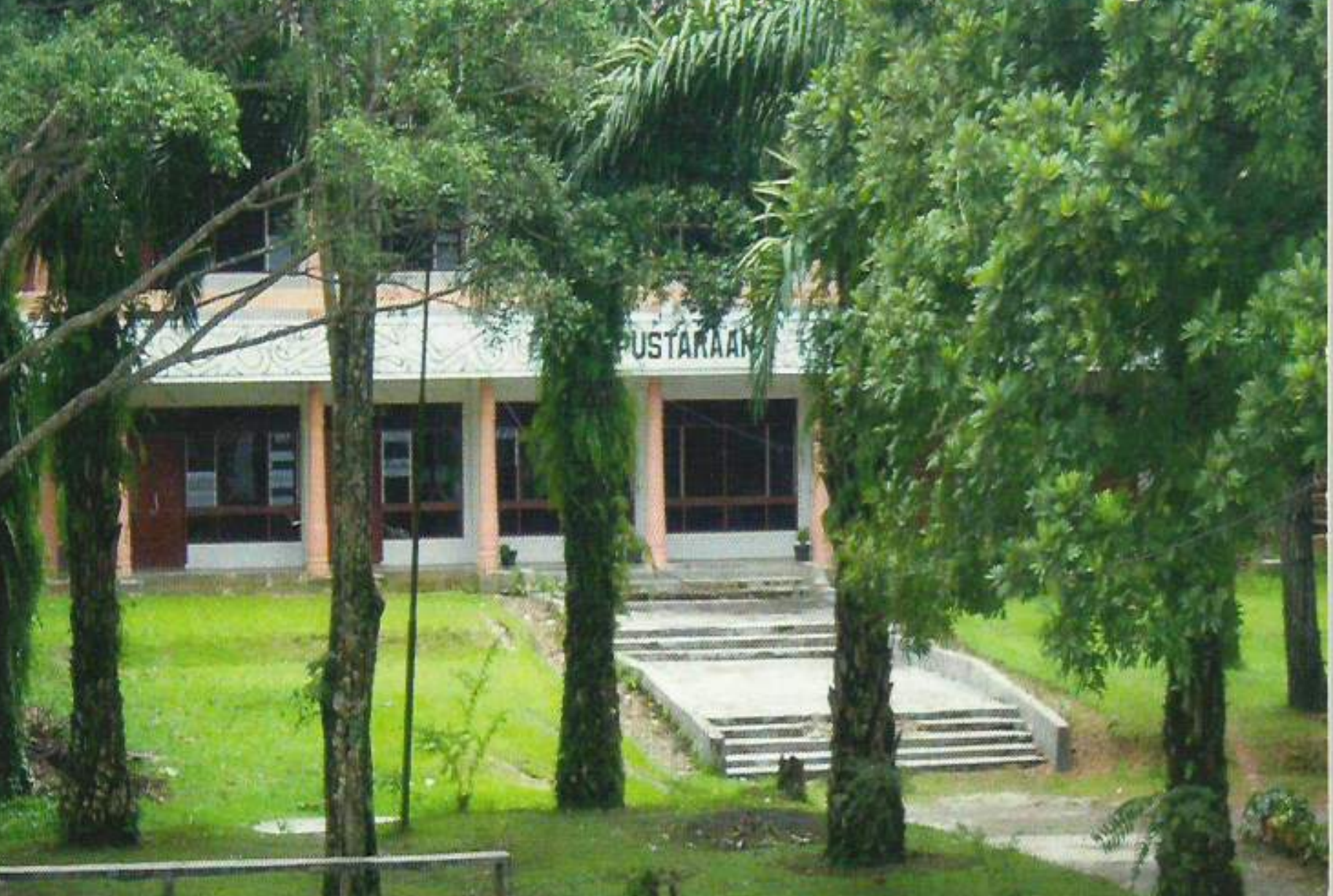


Penasehat

Ulung Napitu, Drs. M.Si

Penanggung Jawab

Riduan Manik, SH, M.Hum

Pengarah

Hisarma Saragih, Drs, M.Hum

Jonner Purba, Ir, MP

Rahamen Saragih, SH, M.H

Pimpinan Redaksi/Editor

Sarintan Efratani Damanik, S.Hut, M.Si

\author{
Anggota Redaksi \\ Warlinson Girsang, Ir, MP \\ Ridwin Purba, Drs. M.Pd \\ Jen Riswandi Damank, SH \\ Noco Yahya Saragih, ST., MT \\ Jalatua Hasugian, S.Pd \\ Pawer Darasa Panjaitan, SE
}

\begin{abstract}
Penerbit
Lembaga Penelitian dan Pengabdian kepada Masyarakat

Universitas Simalungun
\end{abstract}

\author{
Alamat Redaksi \\ Lembaga Penelitian dan Pengabdian kepada Masyarakat (LPPM-USI) \\ Gedung Biro Rektor USI Lantai 2 JI. Sisingamangaraja Pematangsiatar 21139 \\ Telp. 0622-24670, Fax 062-430071, http://www.usi.ac.id \\ e-mal: Ippm usi@yahoo.com
}




\section{DAFTAR ISI}

Sistem Pengawasan Intern Pembelian Bahan Baku Pada Pt.Perkasa Mostindo Utama Medan (PMU) Medan

Elfina O.P Damanik, SE.MM

Profil Pendidikan Indonesia Masa Depan Berbasis Local Wisdom

Muhammad Komarul Huda, M.Pd

Analisis Willingness to Pay (WTP) Masyarakat Terhadap Peningkatan

Kualitas Jasa Pembuangan Sampah Di Kelurahan Nagapita, Kecamatan Siantar Martoba, Kota Pematangsiantar

Darwin SE, M.SE

Kajian Peranan Kewirausahaan Sosial

Liharman Saragih, SE.MM

Evaluasi Fungsional Stasiun Kereta Api Kota Pematangsiantar

Ade Kurnia Harahap 


\title{
SISTEM PENGAWASAN INTERN PEMBELIAN BAHAN BAKU PADA PT.PERKASA MOSTINDO UTAMA MEDAN (PMU) MEDAN
}

\author{
Oleh : \\ Elfina O.P Damanik,SE.MM. \\ Dosen Fakultas Ekonomi Universitas Simalungun
}

\section{Ringkasan}

Penelitian ini dilakukan pada PT. Perkasa Mostindo Utama (PMU) Medan yang bertujuan untuk mengetahui sistem pengawasan intern terhadap pembelian bahan baku pada perusahaan tersebut. Untuk mendapatkan informasi dari data-data tersebut penulis mengunakan metode analisis deskriptif yaitu proses pengolongan atau pengelompokan data sehingga memberikan suatu gambaran mengenai kondisi yang diteliti dan metode analisis deduktif yaitu membandingkan antara teori-teori dengan kenyataan yang terjadi sebenarnya pada perusahaan.

Hasil penelitian menunjukkan bahwa PT. Perkasa Mostindo Utama (PMU) Medan mengunakan sistem pengawasan intern pembelian bahan baku mengunakan dokumen-dokumen yang meliputi surat pesanan pembelian, surat pengantar barang, faktur penjualan, tanda terima barang dan bukti kas keluar.

Kata kunci : pengawasan intern, pembelian, bahan baku.

\section{PENDAHULUAN}

A. Latar Belakang Masalah

Setiap perusahaan memiliki tujuan utamanya adalah untuk mencari laba yang sebesar-besarnya (going concer) dengan biaya yang sekecil kecilnya. Untuk mencapai tujuan tersebut diperlukan proses yang panjang, salah satunya diperlukan sistem pengawasan intern terhadap pembelian bahan baku yang merupakan pintu keluarnya uang perusahaan.

PT. Perkasa Mostindo Utama (PMU) merupakan perusahaan swasta yang bergerak dalam bidang memproduksi obat anti nyamuk bakar tiga roda yang berlokasi di jalan Raya Medan-Binjai Sumatera Utara.

Sistem pengawasan intern pembelian bahan baku pada PT Perkasa Mosindo Utama (PMU) Medan terjadi penyimpangan sehingga terjadi kerugian yang sangat mempengaruhi proses jual beli barang.

\section{B. Perumusan Masalah}

Rumusan masalah dalam penelitian ini adalah "apakah ada kecurangan yang dilakukan oleh pihak yang menerima barang/bagian gudang dengan pihak yang mencatat barang?" 


\section{Tujuan Penelitian}

Penelitian ini bertujuan untuk mengetahui dan memahami sitem pengawasan intern terhadap pembelian bahan baku antara pihak menerima barang dengan pihak yang mencatat barang di PT. Perkasa Mostindo Utama (PMU).

\section{KAJIAN TEORITIS}

\section{A. Pengertian Sistem Pengawasan Intern}

Pengawasan (controlling) merupakan salah satu fungsi dari manajemen, berarti fungsi setiap menejer yang diserahi tugas dan tanggung jawab dalam ruang lingkup bidangnya masing-masing untuk melaksanakan rencana (planning) yang juga merupakan salah satu fungsi dari manajemen (Purba,1996).

Pengawasan intern mencakup struktur organisasi dan seluruh metode serta prosedur yang, terkoordinir yang diterapkan oleh perusahaan untuk mengamankan hartanya, mencek ketelitian dan kepercayaan terhadap datg âkuntansi, mendorong kegiatan agar efisien, dan mengajak untuk mentaati kebijakan perusahaan (Harahap,1991). Ada beberapa hal yang harus diketahui oleh perusahan tentang pengawasan intern,yaitu: 1). Sistem pengawasan intern adalah tanggung jawab manajemen, penerapan sistem pengawasn intern adalah merupakan tugas dan tanggung jawab manajemen perusahaan bukan auditor. Manajemen lah yang paling beruntung apabila perusahaan memiliki sistem ppengawasan intern yang baik dan efektif. Dengan baiknya sistem tersebut berarti manajemen merasa aman dan yakin karena: (a) harta perusahaan akan terjaga dari kemungkinan penyalahgunaan dan penyelewengan baik yang dilakukan pihak internal maupun pihak eksternal perusahaan, (b) informasi yang dihasilkan oleh sistem informasinya akan lebih akurat, tepat waktu, dan murah, (c) kegiatan perusahaan akan berjalan efisien, (d) setiap prosedur yang dianut akan mendorong ditaatinya kebijakan yang dianut antara lain :tingkat keyakinan yang wajar.

Pengertian yang dianut dalam sistem pengawsan intern ini bersifat mutlak, artinya hasil yang diperoleh dari sistem tersebut tidak dapat dijamin bahwa harta perushaan mutlak terjamin tidak diselewengkan untuk tujuan pribadi 1) sistem processing data yang dipakai, sistem pengawasan intern bersifat netral terhadap metode pengolahan data yang digunakan, apakah manual, mekanis atau computer (EDP), 2) Keterbatasan sistem pengawasan intern, keterbatasan ini misalnya disebabkan karena kerjasama (coolusion), " kong kali kong" diantara pelaksanaan sistem itu sendiri, kurang terampilnya pegawai, keterbatasan kemampuan pegawai, sifat lupa dan tiadanya dukungan dari pimpinan tertinggi perusahaan...

Prinsip-prinsip internal control dalam prosedur pembelian menurut Baridwan (2007) adalah sebagai berikut: 1) diadakan pemisahan fungsi yang jelas untuk pihak-pihak: meminta pembelian, melakukan pembelian, menerima barang, menyimpan barang, mencatat terjadinya pembelian dan timbulnya utang. 2). Mengeluarkan uang untuk membayar pembelian (utang): (1). setiap pembelian harus didasarkan pada permintaan pembelian dan dengan harga yang bersaing serta kuantitas yang optimal, 
(2). Bagian pembelian harus mengikuti pengiriman barang-barang dari penjual untuk memastikan ketepatan waktunya : barang-barang hanya akan diterima apabila sesuai dengan spesifikasi dalam order pembelian, faktur pembelian diperiksa kebenaranya sebelum disetujui untuk dibayar, distribusi debit dari barang-barang atau jasa yang dibeli harus dilakukan dengan benar sehingga laporan-laporan untuk pimpinan datanya dapat dipercaya.

\section{B. Pengertian sistem Pembelian}

Menurut Mulyadi (1992), fungsi pembelian adalah tanggung jawab untuk memperoleh informasi mengenai harga barang, menentukan pemasok yang dipilih oleh pengadaan barang, dan mengeluarkan order pembelian kepada pemasok yang dipilih.

Dari fungsi diatas pihak menejer juga harus memperhatikan sistem pemprosesan transaksi pembelian yang dilaksanakan di dalam perusahaan tersebut, dengan tujuan untuk memastikan bahwa semua pesanan dilaksanakan berdasarkan kebutuhan barang pesanan diterima dalam kondisi baik, barang yang diterima masuk kegudang dalam keadaan lengkap, bahwa pembelian tersebut dicatat dan diklasifikasikan secepatnya secara akurat.

Adapun organisasi yang terkait didalam pelaḱsanaan sistem pembelian menurut Mulyadi ada 7 yaitu: bagian gudang, bagian pembelian, bagian penerimaan, bagian jurnal, buku besar, dan laporan, bagian kartu persediaan dan kartu biaya, bagian utang, bagian pengiriman. Catatan akuntansi yang digunakan untuk mencatat transaksi pembelian adalah sistem voucher, register bukti kas keluar, jurnal pembelian, kartu utang, dan persediaan.

\section{Pengertian Bahan Baku}

Pada umumnya setiap perusahaan industri mempunyai 3(tiga) jenis persediaan yaitu: persediaan bahan baku, persediaan dalam proses, dan persediaan barang jadi. Pengertian bahan baku menurut Purba (1995), bahan baku merupakan bahan pokok dan bahan langsung (direct material) yang digunakan dalam proses produksi, seperti tepung terigu dalam perusahaan roti, kain dalam perusahaan garmen dan sebagainya.

Tujuan penerapan sistem pengawasan intern dalam sistem pembelian bahan baku, yaitu: (1) tujuan pengawasan akuntansi : pengawasan akuntansi ditujukan untuk menjaga kekayaan perusaahaan yang berkaitan dengan pembelian bahan baku dan juga bertujuan untuk mengecek ketelitian data yang berhubungan dengan pembelian. Pengecekan ini dimaksud untuk menguji dan mengetahui keandalan data tersebut, sehingga dapat disajikan secara benar dan dapat dipercaya. Data ini digunakan sebagai bukti dalam penyusunan laporan keuangan perusahaa, dimana pengecekan data tersebut dapat dilakukan dengan cara menghitung kuantitas dari barang yang dibeli dan membandingkan dengan dokumen yang terkait. Dengan adanya pengawasan ini diharapkan kesalahan dan kecurangan dalam pelaksanaan pembelian dapat dihindari. (2) tujuan pengawasan administrasi : pengawasan ini bertujuan untuk mendorong tercapainya efisiensi operasional perusahaan. Efisiensi operasional ini sangat berguna bagi pihak manajemen di dalam membuat kebijakan yang menyangkut kegiatan pembelian dalam menentukan supplier. Dengan dipatuhinya kebijakkan tersebut dapat membantu manajemen dalam pengawasan terhadapa operasional perusahaan dan pengambilan keputusan terhadap pembelian bahan baku. 
Tujuan pokok dari pengawasan intern (internal control) antara lain (Purba,1996): 1) menjaga kekayaan perusahaan selalu aman, 2) Mengarahkan dan meluruskan penyimpangan dan memperbaiki kesalahan yang terjadi dalam pelaksanaan tugas 3) mengusahakan agar perusahaan bekerja efisien, dan efektif dan semua aktivitas diarahkan kepada tujuan, 4) membina dan mendorong adanya ketaatan untuk menjalankan kebijaksanaan yang digariskan oleh pimpinan. 5 mengecek kebenaran (reliability) dan ketelitian (accuracy) dari data akuntansi, 6) melalui conduite para karyawan khusus para menejer, 7) mencek apakah rencana (anggaran) perlu direvisi atau tidak, demikian juga apakah sasaran (tujuan) perlu diubah atau tidak, 8) mencek apakah struktur organisasi atau sistem administrasi yang digunakan perlu direvisi atau tidak.

Untuk mencapai tujuan di atas, manajemen perusahaan bertanggung jawab merancang dan menerapkan lima unsur pengendalian internal, unsur-unsur tersebut adalah: 1) lingkungan pengendalian, 2) penilaian resiko, 3) prosedur pengendalian, 3) pemantauan atau monitoring, 4) informasi dan komunikasi (Niswonger, 2009)

\section{METODE PENELITIAN}

Untuk mendapatkan informasi yang diperlukan dalam penelitian ini mengunakan dua jenis metode pengumpulan data yaitu: metode penelitian kepustakaan (library research) atau berupa data sekunder yaitu penelitian dilakukan dengan bahan bacaan untuk memperoleh input yang relevan seperti: literature, bahan kuliah, dan artikel-artikel, dan metode penelitian lapangan (field research) yaitu dengan mengunakan penelitian langsung ke PT. Perkas Mostindo Utama (PMU) yang bertujuan untuk memperoleh data dan informasi serta bukti-bukti tentang sistem pengawasan pembelian bahan baku yang dilakukan perusahaan tersebut, melalui observasi dan wawancara kepada pegawai yang berada dibagian pembelian.

Adapun metode analisis yang digunakan dalam penelitian ini yaitu metode analisis deskriptif sehingga dapat memberikan suatu gambaran mengenai kondisi yang ada atau masalah yang diselidiki dan metode analisis deduktif adalah membandingankan antara teori-teori dengan kenyataan yang terjadi sebenarnya pada perusahaan tersebut.

\section{IV.PEMBAHASAN}

PT. Perkasa Mostindo Utama (PMU) Medan merupakan suatu perusahaan swasta yang bergerak di bidang industri obat anti nyamuk yang beralamat di Jalan Raya Medan-Binjai. Perusahaan ini mengunakan bahan baku sebagai bahan utama bagi suatu perusahaan industri untuk memulai produksi, oleh karenanya pembelian baku tersebut biasanya merupakan sumber pengeluaran kas yang besar bagi perusahaan.

Pengawasan intern atas pembelian bahan bahan baku ini sangat diperlukan bagi perusahaan, sebab apabila pembelian bahan baku ini tidak diawasi dengan baik, maka akan memberikan peluang bagi personil yang tidak bertanggung jawab untuk melakukan kecurangan ataupun kemungkinan adanya kesalahan dalam prosedur yang justru akan menimbulkan kerugian bagi perusahaan. 
Pembelian bahan baku yang diiakukan PT.Perkasa Mostindo Utama (PMU) beruasarkan kebutuhan bagian produksi dengan prosedur : 1) pada saat ada permintaan bahan baku dari bagian produksi atau bagian gudang, maka bagian logistik akan memberitahukan kepada Factory Manager, kemudian Factory Manager akan mengintruksikan bagian pembelian untuk melakukan pembelian bahan baku.

Adapun dokumen-dokumen yang di pergunakan oleh PT.Perkasa Mostindo Utama (PMU) untuk melakukan transaksi pembelian bahan baku meliputi: 1) Surat Pesanan Pembelian, 2) Surat Pengantar Barang, 3) Faktur Penjual dari Supplier, 4) Surat Tanda Terima Barang dan 5) Bukti Kas Keluar.

Jenis-jenis pengawasan intern pembelian bahan baku PT. Perkasa Mostindo Utama (PMU) mencakup: 1) Pengawasan kuantitas pembelian bahan baku : kuantitas pembelian bahan baku pada PT.Perkasa Mostindo Utama disesuaikan dengan kebutuhan untuk memenuhi kegiatan produksi selama satu bulan dan juga jumlah persediaan bahan baku yang ada digudang, artinya untuk menentukaan jumlah (kuantitas) bahan baku yang harus dibeli dan bagian pembeli harus mengetahui berapa jumlah yang dibutuhkan untuk memenuhi kegiatan produksi selama satu bulan dan berapa jumlah persediaan yang masih ada di gudang. 2) Pengawasan kualitas pembelian bahan baku : bahan baku yang digunakán oleh PT. Perkasa Mostindo Utama (PMU) terdiri dari tepung onggok, tepung kayu, tepung batok, tepung byket, unsurunsur kimia dan parfum. Semua bahan baku ini sebelum dimasukkan ke dalam gudang yang berbentuk sebuah ruangan untuk diteliti kualitasnya di laboratorium perusahaan oleh bagian quality control / lab. Hasil pemeriksaan ini diberitahukan secara lisan atau memo ke bagian pembeli untuk mengetahui kualitasnya telah sesuai dengan surat pesanan pembelian.

Prosedur pembelian bahan baku PT. Perkasa Mostindo Utama (PMU) di mulai adanya kebutuhan atas suatu barang oleh bagian gudang tersebut. Adapun bagian-bagian yang terlibat dalam prosedur pembelian bahan baku ini adalah: bagian gudang, bagian pembelian, bagian produksi, bagian keuangan/accounting dan Factory Manager (FM)

\section{KESIMPULAN DAN SARAN}

\section{A. Kesimpulan}

Setelah dilakukan penelitian Sistem Pengawasan Intern Pembelian Bahan Baku pada PT. Perkasa Mostindo Utama (PMU) Medan :

1. Bahwa perusahan tersebut sudah baik dalam melakukan pengawasan intern pembelian bahan baku, karena dilakukannya pengawasan kuantitas dan kualitas dari bahan baku tersebut, hanya saja pengawasan terhadap harga tidak ada sehingga dapat menimbulkan kecurangan terhadap harga bahan baku.

2. Dalam melaksanakan prosedur pembelian bahan baku menggunakan dokumen-dokumen yang meliputi Surat Pesanan Pembelian, Surat Pengantar Barang, Faktur Penjualan. Tanda Terima Barang dan Bukti Kas Keluar kurang lengkap untuk mendukung pengawasan intern yang baik atas pembelian bahan baku, karena masih ada dokumen yang belum digunakan perusahaan tersebut yaitu Surat Permintaan Pembelian, dan Surat Permintaan Penawaran Harga, sehingga dapat timbul kecurangan dalam penentuan harga yang terlalu tinggi. 
3. Sistim pengawasan intern pembelian bahan baku yang dilakukan PT.Perkasa Mostindo Utama (PMU) Medan kurang diimbangi dengan pemakaian pegawai yang berkompeten dalam bidang pembelian yang dapat mengakibatkan system pengawasan intern tersebut tidak mampu mengatasi kebocoran biaya perusahaan, sehingga peningkatan laba secara maksimum tidak dapat dicapai.

B. Saran

Untuk meningkatkan efektifitas pengawasan intern pembelian bahan baku sebaiknya perusahaan memiliki bagian khusus yang bertugas menerima dan menyimpan barang bahan baku serta dalam melakukan permintaan pembelian, bagian gudang jangan hanya secara lisan atau mengunakan memo saja, tetapi disarankan agar perusahaan sebaiknya mengunakan Surat Permintaan Pembelian yang diberi nomor urut tercetak dan dibuat dalam beberapa tembusan yang diperlukan dan sebaikmya perusahaan terlebih dahulu mengirimkan Surat Penawaran Harga kepada beberapa supplier serta pihak manajemen harus benar-benar memperhatikan terhadap pemilihan dan penempatan pegawai yang berkompeten dan jujur pada bagian tersebur.

\section{DAFTAR PUSTAKA}

Sistem Akuntansi,Salemba Empat, UGM,Yogyakarta, 2001

Baridwan, Zaki,Sistem Akuntansi Penyusunan Prosedur dan Metode, BPFE. Yogyakarta,2007

Sofyan S. Harahap, Auditing Contemporer, Erlangga, Jakarta, 1991

Mulyadi, Pemeriksaan Akuntansi,UGM, Yogyakarta,1992

C.Rollin Niswonger et.al., Prinsip-Prinsip Akuntansi, Erlangga, 2009

Radiks Purba, Akuntansi untuk Menejer, Jilid Dua,Cetakan Pertama: Rineka Cipta, Jakarta,1995 